\title{
A DOCÊNCIA NO ESTÁGIO PÓS-DOUTORAL COMO PROCESSO DE FORMAÇÃO PROFISSIONAL: RELATO DE EXPERIÊNCIA
}

\section{DOCENCY IN POST DOCTORAL AS A PROFESSIONAL TRAINING PROCESS: EXPERIENCE REPORT}

\author{
Sergio Vale da Paixão* \\ Renilson José Menegassi *
}

\begin{abstract}
Resumo: este artigo tem como objetivo relatar a experiência vivida na docência no ensino superior no estágio pós-doutoral em que se problematizou o uso de tecnologias para fins didáticos nas aulas de Língua Portuguesa. A temática do Letramento Digital foi o ponto de partida para os trabalhos em um curso com acadêmicos de Letras da Universidade Estadual de Maringá-PR, outras temáticas também importantes emergiram, tais como: o papel de autoridade do professor nas escolas da atualidade e a avaliação da aprendizagem nas atividades propostas com o uso de tecnologias para fins de aprendizagem e avaliação. O trabalho foi realizado com uma carga horária de dez horas, de acordo com a proposta do programa de pós-graduação e teve como fundamento teórico as pesquisas de autores importantes na temática do Letramento Digital: Coscarelli; Ribeiro (2007), Coscarelli (2016), Levy (1999), Rojo \& Moura (2012); e Paixão (2012; 2016).
\end{abstract}

Palavras chaves: letramento digital; formação de professores; tecnologias.

\begin{abstract}
: this article has as main objective to report the experience lived in the teaching in the postdoctoral higher education in which the use of technologies for didactic purposes in the classes of Portuguese Language was problematized. The theme of Digital Literacy was the starting point for the beginning of the work in a course with students of of Letters of the State University of Maringá - PR and, from this theme, others also important emerged, such as; the role of teacher authority in today's schools and the evaluation of learning in the proposed activities using technologies for learning and evaluation purposes. The work was carried out with a workload of ten hours, according to the proposal of the postgraduate program and had as theoretical foundation the researches of important authors in the subject of Digital Literacy, such as Coscarelli; Ribeiro (2007), Coscarelli (2016), Levy (1999), Rojo \& Moura (2012); and Paixao (2012, 2016).
\end{abstract}

Keywords: digital literacy; teacher training; technologies.

\section{Introdução}

A rotina a que nós professores nos encontramos ao longo do período letivo, em muitos casos, colabora de forma efetiva para que as aulas, bem como a organização e os planejamentos de trabalho, permaneçam em estado estacionário, ou seja, não há inovações, criatividades e, consequentemente, reflexões sobre a prática pedagógica. Ainda que nossa experiência em sala de aula seja intensa na educação básica e no ensino superior, a possibilidade e a oportunidade de se experienciar novos espaços de trabalho com culturas escritas diferentes, diferentes contextos e, naturalmente, diferentes estudantes, colaboram de modo significativo para a ampliação do repertório profissional e fortalece o fazer pedagógico, pois se oportunizam novos olhares em direção ao devir, visto que, ao sair do contexto natural onde o professor já se encontra ambientado, tem-se a oportunidade de observar, muito mais do que olhar, outras formas do agir pedagógico por uma ótica externa. A partir disso, acreditamos que, com essa mudança de ambiente, inicia-se uma auto etnografia (SANTOS; BIANCALANA,

\footnotetext{
Professor doutor do Instituto Federal do Paraná - campus Jacarezinho. E-mail: sergiovpaixao@hotmail.com

* Professor doutor da Universidade Estadual de Maringá - PR. E-mail: renilson@ wnet.com.br
} 
2017), o que amadurece e fortalece as crenças e dúvidas inerentes ao papel do professor em sala de aula.

Esse texto procura relatar a experiência ocorrida no cumprimento de uma das exigências do estágio de Pós-Doutorado do Programa de Pós-graduação em Letras na Universidade Estadual de Maringá-PR, quando propusemos um curso de dez horas aos estudantes do $3^{\circ}$ ano de Letras para se problematizar a teoria e a prática na utilização dos recursos tecnológicos no ensino de Língua Portuguesa.

A iniciativa da temática escolhida para o curso se deu a partir do interesse manifestado pelos acadêmicos sobre o tema que sempre se mostrou crítica sobre o assunto, de acordo com o supervisor da pesquisa, que também lecionava para a turma. Assim, alinhamos nossa experiência como formadores de professores nos cursos de licenciaturas, além de pesquisas que realizamos acerca das linguagens e das tecnologias no ambiente da escola, e propusemos reflexões teóricas e práticas ao longo do curso sobre o tema do Letramento Digital e suas implicações para o ensino e a aprendizagem.

$\mathrm{O}$ curso ocorreu em duas etapas distintas, divididas em duas manhãs consecutivas de segundas-feiras e contou com a participação de aproximadamente 30 acadêmicos. Todos os trabalhos e diálogos propostos levaram em consideração as exigências de se pensar o papel do educador, em especial o de Língua Portuguesa, em contextos atuais de ensino. Foi necessário utilizar um escopo teórico que pudesse nos sustentar nas atividades e diálogos com a temática abordada, advindos de pesquisadores contemporâneos sobre a temática do Letramento Digital, tais como Coscarelli \& Ribeiro (2007), Coscarelli (2016), Levy (1999), Rojo \& Moura (2012); e Paixão (2012; 2016).

O resultado do trabalho superou nossas expectativas, pois pudemos verificar uma profícua participação dos envolvidos no curso. Outra situação que merece aqui ser destacada é o resultado importante que o curso trouxe para nossa formação profissional. $\mathrm{O}$ que passaremos a relatar a seguir revela a participação e o engajamento dos acadêmicos envolvidos, que são provas pontuais para nossas considerações finais.

\section{RELATO DE EXPERIÊNCIA}

\subsection{Primeiro dia}

Para o primeiro encontro com duração de cinco horas foram eleitos os seguintes conteúdos para se trabalhar com o grupo: a) Concepções de redes sociais; b) Processo de leitura e escrita; c) Formação e desenvolvimento do leitor nas redes sociais da internet; d) Atividades práticas. Os conteúdos elegidos para o trabalho para o primeiro momento se justificam pela forma como planejamos o curso, observando as necessidades de se discutir o Letramento Digital com acadêmicos do curso de Letras, já que temos desenvolvido atividades nessa direção com outros professores em formação e, principalmente, pela demanda apresentada pelo grupo ao professor que lecionava para a turma e supervisionou o estágio pós doutoral e o curso ministrado.

O encontro com os acadêmicos teve início no dia 6 de agosto de 2018, no período da manhã. Foi necessário apresentar aos acadêmicos parte da nossa trajetória acadêmica e profissional desde o início da carreira docente, para que pudéssemos justificar nossas motivações e interesses de pesquisa com o tema do Letramento Digital. Iniciamos o trabalho apresentando nossas motivações e inquietações como docentes de Língua Portuguesa no início de carreira profissional no ano de 2003, quando preocupados com melhores resultados nas avaliações e atividades realizadas com os alunos, notávamos uma necessidade de se atualizar a forma de lecionar às crianças, adolescentes e jovens, buscando aproximar os conteúdos curriculares às realidades das turmas. A partir dessa discussão, apresentamos também os resultados advindos de nossas pesquisas, primeiramente no mestrado no Programa de Pós Graduação em 
Estudos da Linguagem na Universidade Estadual de Londrina (UEL), sob o título "Produção de Textos e Letramento Digital: interfaces na escola e nas redes sociais" (PAIXÃO, 2012), em que pudemos problematizar as produções escritas dos alunos do ensino médio realizadas nas escolas e também nas redes sociais da internet. A partir daí, apresentamos parte do trabalho realizado no processo de doutoramento no Programa de Pós-graduação em Psicologia, na Universidade Estadual Paulista (UNESP), intitulada "Sentimentos na Rede e Educação: um estudo a partir das narrativas de jovens no Facebook" (PAIXÃO, 2017), em que analisamos o espaço da internet como território de publicações de sentimentos. Além disso, outras produções científicas foram realizadas e publicadas ao longo de nosso trabalho como professores e pesquisadores para se problematizar o papel das tecnologias no ambiente escolar, o que colaborou significativamente para o que estávamos propondo naquele curso.

$\mathrm{O}$ intuito era o de motivar e incentivar os professores em formação e fomentar discussões sobre o atual contexto pouco produtivo da inserção das novas tecnologias no ambiente escolar a fim de refletir como podem explorar os recursos digitais para inserção dos alunos em contextos sociais de uma nova cultura, reconhecida por Lévy (1999) como Cibercultura, definida pelo autor como "o conjunto de técnicas (matérias e intelectuais, de pensamento e de valores que se desenvolvem juntamente com o crescimento do ciberespaço ou rede)" (LÉVY, 1999, p. 17).

No decorrer das apresentações, foram surgindo interesses dos acadêmicos sobre nossa prática pedagógica em aulas de Língua Portuguesa, principalmente no Ensino Médio, pois fomos nos apegando nos exemplos já realizados com os alunos nesse nível de ensino para exemplificar nossas práticas. A forma de se organizar as atividades, a recepção por parte da família sobre o uso das tecnologias na sala de aula, as formas de avaliar as aprendizagens, a abordagem com os alunos, a possível indisciplina a partir dos usos das tecnologias durante as aulas, dentre outros assuntos, foram algumas das iniciais preocupações e questionamentos trazidos pelos acadêmicos. As dúvidas foram sendo sanadas com uma apresentação de slides que utilizamos, mostrando-lhes atividades que temos feito com a utilização de recursos midiáticos e redes sociais da internet para o incentivo à leitura e à produção escrita (COSCARELLI, 2016; COSCARELLI; RIBEIRO, 2007; RIBEIRO, 2012).

A interação dos acadêmicos com os conteúdos que foram inicialmente apresentados, ou seja, os exemplos que trouxemos de atividades já realizadas em nossas aulas de Língua Portuguesa, quando utilizamos recursos tecnológicos para a preparação e planejamentos, bem como conosco, foi motivador e intenso, especialmente quando mostraram o interesse no desenvolvimento de aulas de Língua Portuguesa em que o uso de celulares, computadores e redes sociais da internet foram utilizados para fins didáticos. Procuramos, no início de nossas apresentações, ilustrar como nossas aulas têm se organizado e sido planejadas quando utilizamos os artefatos das tecnologias para fins de aprendizagem e ensino. Com ilustrações e exemplos do que desenvolvemos na prática, aos poucos, fomos apresentando uma série de atividades e ideias de utilização dos recursos de tecnologias que fazem parte do dia a dia dos acadêmicos, mostrando como utilizá-los para fins de ensino em sala de aula. Uma das atividades em que os acadêmicos melhor se identificaram foi quando apresentamos o exemplo de uma aula sobre o uso dos sinais diacríticos, em especial as reticências e as aspas realizadas no Facebook como atividade para ser realizada em casa. A todo o momento, o grupo de acadêmicos era questionado sobre o sentido que aquelas apresentações de conteúdo, em forma de exemplos, estava fazendo para eles, considerando que são mais que simplesmente acadêmicos, mas professores em formação e também considerados, muitos deles, nativos digitais, ou seja, nascidos em tempos em que a internet e os 
recursos das tecnologias já se faziam presentes na vida social do homem, conforme Prensky (2016).

O feedback dado pelos acadêmicos, a partir de nossas indagações sobre os conteúdos apresentados no curso, era constantemente positivo e motivador. Todo aquele conteúdo sobre o uso de tecnologias para o ensino e aprendizagem que propusemos a apresentar ao grupo, mostrando que as páginas da internet e das redes sociais podem ser vistas como grandes possibilidades e espaços adequados para se ensinar línguas e literatura por terem potencialidades de recursos, estava realmente fazendo sentido a eles, de acordo com o que relatavam oralmente. Alguns diziam que nunca haviam pensado na possibilidade da utilização dos recursos digitais para fins didáticos "na mão dos alunos", mas, sim, como ferramenta utilizada exclusivamente pelo professor para ministrar suas aulas, referindo-se ao computador, projetor multimídia, caixa de som dentre outros. Tal crença ratifica os postulados de Tardiff $(2008$, p. 16) ao afirmar que "o saber dos professores parece estar assentado em transações constantes entre o que eles são (incluindo as emoções, a cognição, as expectativas, a história pessoal deles etc.) e o que fazem."

Ao longo do período da manhã, os exemplos de atividades apresentadas, tais como,, produção escrita e desenvolvimento de leitura na tela do computador e celulares, produção de narrativas com o uso da música e do fone de ouvido, análise linguística a partir de textos publicados nas redes sociais da internet e, principalmente, o conceito sobre Letramento Digital, ou seja, a capacidade de realizar ações de leitura e escritas digitais bem sucedidas como parte de situações da vida cotidiana, eram apresentados na prática, alinhando sempre a um escopo teórico que fundamentasse aquela exposição (COSCARELLI; RIBEIRO, 2007,);,(COSCARELLI, 2016,); ,(LEVY, 1999,); ,(ROJO; MOURA, 2012).

Nesse primeiro momento, procuramos trazer e apresentar o escopo teórico que fundamenta nossas aulas quando o assunto é a leitura e a produção escrita dos alunos do ensino médio e superior, mostrando na prática como é possível a utilização de recursos tecnológicos disponíveis no dia a dia dos alunos e também dos professores para o favorecimento das práticas de letramento. Acreditamos, nesse sentido, que a compreensão do conceito de Letramento Digital "nos ajuda a entender o leitor que vem surgindo com a multiplicidade de textos e as mensagens que transitam na comunicação em rede, uma vez que às complexas tarefas exigidas na leitura do impresso somam-se a outras quando nos colocamos diante dos textos digitais." (ZACHARIAS, 2016, p.21).

Alinhando a teoria e a prática, na apresentação das atividades possíveis e já realizadas por nós em aulas de Língua Portuguesa, conforme demonstramos a eles por meio dos slides que nos auxiliaram ao longo do curso, foi possível um contato mais próximo da realidade que possam encontrar em suas salas de aula já que o grupo se constitui de futuros professores, e, aos poucos, provocávamos a pensar em ideias para desenvolvimento de novos formatos e organizações didáticas, sem cópias, sem reproduções, mas de criações inovadoras e iniciativas próprias.

A maioria dos participantes, mesmo observando a participação ativa que nossos alunos da Educação Básica tiveram com as atividades propostas, já que a todo o momento deixamos claro que os exemplos apresentados eram oriundos de nossas aulas em turmas de Ensino Médio e, em alguns casos, do Ensino Superior, mostrou-se preocupada com a "descentralização" do professor como "autoridade" em sala de aula.

Nos momentos iniciais do encontro, ficou-se a impressão de que os participantes do curso, embora bastante atentos, não confiavam na proposta defendida e apresentada de que a produção escrita dos alunos da educação básica com a utilização das redes 
sociais e com as tecnologias de interação e comunicação possam construir um ambiente motivador e criativo de aprendizagem na sala de aula, pelo contrário, tivemos a impressão, com seus posicionamentos, de que a permissão para o uso desses artefatos tecnológicos e virtuais de comunicação, mesmo que sob orientação do professor, pudesse acarretar em desordem, indisciplina e na não participação dos estudantes durante as aulas.

Problematizamos, portanto, que a evasão e a indisciplina dos estudantes nas escolas, assunto de longa data debatido por profissionais da educação, possam ser amenizadas a partir da construção de um ambiente de aprendizagem com a colaboração das tecnologias, uma vez que se tem uma nova configuração dos espaços de ensino quando a escola e professores se propõem a realizar atividades que dialoguem com suas realidades.

É nesse sentido que considerar a mediação dos diversos artefatos digitais que faz parte dos cotidianos dos jovens dentro ou fora do ambiente escolar, ajuda a pensar a constituição da subjetividade na contemporaneidade e também a construção do conhecimento. (FERREIRA; OSWALD; CHAVES, 2015, p.2014).

Além disso, e para sustentar nossa defesa, apegamo-nos em estudos sobre o uso das tecnologias em sala de aula como recursos educativos que mostram que os professores ainda se posicionam com dúvidas e dificuldades no uso de certos artefatos tecnológicos não apenas para fins didáticos, mas, também, para usos pessoais, o que dificulta sobremaneira a utilização desses recursos pelos profissionais docentes.

De acordo com Ribeiro (2016, p.161),

Muitos se apropriam de filmes, vídeos, músicas, jogos, dentre outros com fins didáticos pouco claros e definidos, ou seja, inserem os recursos multimidiáticos apenas como "adornos" para as aulas, na esmagadora maioria das vezes, sem definir objetivos didáticopedagógicos para seu uso nem relacioná-los aos conteúdos de ensino.

Aos poucos, respondendo aos muitos questionamentos que surgiam durante nossa exposição e problematizações acerca dos conteúdos sobre o Letramento Digital, fomos mostrando-lhes que a autoridade do professor, já que o assunto emergiu na fase inicial do curso, está justamente construída na confiança que se cria quando há respeito aos espaços e aos interesses dos alunos (CASCO, 2007), uma vez que devem ser olhados como alunos atuais, imersos em tecnologias e recursos áudio visuais para fazerem uso em suas interações e comunicações sociais diárias, daí, então, a necessidade de se refletir e construir um ambiente de letramentos múltiplos, em que se insere, naturalmente, o digital.

$\mathrm{O}$ encontro nesse primeiro dia encerrou-se com a entrega do artigo "Letramento Digital: possibilidades de trabalho" (ZACHARIAS, 2016), do livro Tecnologias para ensinar, organizado por um expoente no assunto, a professora Carla Vianna Coscarelli, da UFBH (COSCARELLI, 2016). O convite à leitura do texto foi realizada para que os acadêmicos pudessem apreciar o material para darmos o início das atividades que aconteceriam no segundo dia do encontro, na data do dia 13 de agosto de 2018. Encerramos, portanto, o primeiro dia, com uma pequena avaliação oral, na qual os acadêmicos puderam manifestar suas percepções sobre os conteúdos tratados naquele primeiro momento, ou seja, o Letramento Digital, os recursos áudio visuais para o ensino de Língua Portuguesa, o papel do professor diante do uso de tecnologias para 
fins didáticos e, adjacentes a esse tema, a autoridade do professor quando se permite o uso de recursos digitais em sala de aula para fins didáticos.

Os acadêmicos que se manifestaram na avaliação oral e reagiram positivamente à proposta daquele primeiro dia de curso com discursos de que o encontro possibilitou novos olhares sobre o uso de tecnologias na sala de aula, principalmente no que diz respeito ao uso de celulares. Dois dos participantes encerraram o período da manhã, afirmando que estavam saindo do encontro ainda mais pensativos e reflexivos, mas não totalmente convencidos de que o uso de tecnologias para fins didáticos possa trazer benefícios à aprendizagem uma vez que veem seus usos como ferramentas que mais atrapalham do que colaboram para o ensino e a aprendizagem em sala de aula, tomando suas próprias experiências.

\subsection{Segundo dia}

O segundo dia do encontro, na data de 13 de agosto de 2018, tivemos como conteúdos os seguintes temas: a) Avaliação da aprendizagem; b) Educação Integral em tempos virtuais; c) Tecnologias e educação; d) Conceito de Entonação na produção escrita da internet; e) Afetividade e educação. Com a participação ativa dos cursistas, apresentando suas dúvidas e interesses, fez-se necessário um reorganização de pauta dos trabalhos, o que emergiu esses temas. Os temas, agora elencados para o segundo dia de curso, são, portanto, oriundos, a maioria deles, das discussões e apresentadas pelos acadêmicos no primeiro dia.

A manhã iniciou com uma situação interessante e desafiadora: o equipamento de projeção de áudio e vídeo não funcionou no início do curso. Essa situação favoreceu um ambiente para as discussões que seriam realizadas na sequência, ou seja, quando as aulas estão preparadas com recursos tecnológicos e, por questões técnicas, típicas das tecnologias, deixam de funcionar. Tão logo o projetor, bem como o funcionamento da internet na sala de aula, passou a operar, iniciamos a discussão sobre o texto "Letramento Digital: possibilidades de trabalho" (ZACHARIAS, 2016), distribuído e orientado aos acadêmicos como atividade de leitura para ser realizada em casa, na aula anterior. Durante aproximadamente uma hora, os acadêmicos se posicionaram acerca do conteúdo do texto que tratava do conceito de Letramento Digital e as abordagens pedagógicas para o ensino de leitura e escrita, dialogando sobre o conceito proposto pela autora do artigo e aproximando-o do conteúdo prático trabalhado no encontro anterior. A principal proposta apresentada no artigo de leitura foi a compreensão sobre o conceito de Letramento Digital fazendo com que o leitor possa repensar a prática de leitura e escrita em sala de aula para colaborar com a formação dos alunos em sintonia com suas práticas sociais. Além disso, o artigo promove um repensar a prática docente em tempos de tecnologias em que seja necessário levar em consideração os inúmeros recursos atuais disponíveis para fins de ensino e aprendizagem. A avaliação do grupo, a partir da leitura realizada, foi positiva em relação ao que propôs a autora, ou seja, problematizar o uso das tecnologias para fins de leitura e escrita na escola e suas implicações no ensino de línguas (ZACHARIAS, 2016).

Nem todos os acadêmicos cumpriram com a atividade orientada para se fazer em casa realizando a leitura do texto, mas, mesmo aqueles que não leram o material, participaram ativamente das discussões trazidas por aqueles que produziram inúmeras anotações e trouxeram dúvidas sobre o conteúdo do artigo. A maior dúvida surgida no momento da atividade de socialização da leitura entre os acadêmicos foi a de como deve ser realizada a avaliação da aprendizagem nos trabalhos com a tecnologia, já que o assunto sobre a avaliação não foi tratado no artigo de referência e tão pouco no encontro 
anterior, quando abordamos apenas a metodologia de trabalho com o uso de recursos tecnológicos. Ficou evidente no início da discussão o quanto os acadêmicos acreditam que a avaliação deva ser realizada da forma como ocorre há anos em suas trajetórias acadêmicas, ou seja, utilizando-se do papel impresso e datas marcadas para acontecer.

Propusemo-nos a dialogar com o grupo sobre o papel do lúdico nas atividades escolares não apenas para o ensino de crianças na Educação Infantil, mas em todos os níveis de escolaridade e, principalmente, para o que propusemos dialogar, para aulas do Ensino Médio. $\mathrm{O}$ foco de reflexões nesse momento do curso era o de se pensar o lúdico e o jogo, que são próprios de trabalhos realizados nas esferas virtuais de comunicação, como possibilidades de realização de atividades escolares e, por que não, de avaliações da aprendizagem.

Partimos, então, da premissa de que "os jogos são considerados pelos professores apenas como recursos lúdicos que não servem mais para a transmissão de conteúdos nos anos finais do fundamental e ensino médio," (RIBEIRO, 2016, p.165) para desconstruir a ideia e favorecer uma reflexão que pudesse colaborar para se pensar o lúdico como estratégia de interação e aprendizagem. Além disso, nos apegamos em Prensky (2006), que defende a ideia das aprendizagens que emergem nos jogos. Segundo o autor, os jogos oferecem melhorias nos desempenhos escolares, colaboram nas interações com pessoas e ajuda a resolver problemas de forma rápida e independente. Assim, nossa defesa de que a partir das interações que ocorrem no lúdico, nos jogos virtuais e nas inúmeras plataformas já desenvolvidas para a sala de aula, possibilitam um ensino e aprendizagens significativas.

A iniciativa de se pensar o trabalho com os jogos via aplicativos e recursos tecnológicos fez avançar ainda mais a temática da avaliação, já iniciada anteriormente, e que continuou presente principalmente porque, na sequência, apresentamos ao grupo um aplicativo com potencialidades para o trabalho em sala de aula como um instrumento da tecnologia capaz de realizar atividades lúdicas de fixação de conteúdos e a avaliação da aprendizagem não só para aulas de Língua Portuguesa, mas para todo e qualquer conteúdo escolar ou não. Por ocasião da apresentação do aplicativo à turma, bem como a orientação de como se deve utilizar adequadamente o aplicativo em sala de aula consideramos a escola como uma das inúmeras agências de Letramento Digital, conforme Ribeiro (2012) desde que o professor realmente saiba "aonde se quer chegar com o trabalho realizado", conforme comentou uma acadêmica.

$\mathrm{Na}$ ocasião, dando continuidade ao curso, realizamos a atividade que havíamos preparado para aquele momento usando o Kahoot como ferramenta de trabalho para atividades que diziam respeito à literatura e gramática, apenas como forma de mostrar aos participantes a utilização do aplicativo como ferramenta para a aula de Língua Portuguesa. O aplicativo chamou a atenção do grupo pela sua dinamicidade e possibilidades de utilização e não era conhecido por nenhum dos acadêmicos. Trata-se de um recurso possível de ser utilizado por professores - dentre outros usuários - que permite a construção de jogos de perguntas e respostas sobre temas variados. Os temas estão disponíveis em uma plataforma, porém, o professor/usuário consegue criar perguntas e novas atividades para serem aplicadas aos seus alunos de acordo com seus interesses e temáticas variadas.

O aplicativo Kahoot é um sistema de questionários on line criado na Noruega e que está ganhando cada vez mais espaço nas escolas dos EUA. O sistema funciona como um programa de TV aliado a características de um jogo de videogame. Colocando-se no papel de apresentadores, os professores fazem uma pergunta de múltipla escolha sobre qualquer assunto para seus alunos. Utilizando-se da plataforma do Kahoot, projeta-se a pergunta na tela, uma de cada vez, na frente dos alunos 
participantes do jogo. Os jogadores, nesse caso os alunos, têm aproximadamente 30 segundos para clicar na resposta certa em seus laptops ou smartphones. Os jogadores ganham pontos para cada resposta correta, além de pontos extras para quem clicar mais rápido na resposta. Muito mais do que mostrar seu uso, solicitamos que todos pudessem utilizar seus aparelhos celulares para a interação na atividade naquele momento. Apenas quatro dos acadêmicos não participaram sozinhos, pois estavam sem seus smartphones, mas fizeram parcerias em grupos com os que tinham um celular na sala.

Como de costume, quando utilizamos esse aplicativo em sala de aula, os acadêmicos se empolgaram com a proposta, principalmente porque havia uma disputa de quem acertaria as respostas corretas e com menos tempo, pois isso, a agilidade em responder as questões, contabilizava pontos para os participantes e os fazia liderar o ranking de campeões do jogo. Após a atividade, na soma de sete questões propostas para serem respondidas, os acadêmicos se posicionaram com dúvidas de como construir um KAHOOT para fins didáticos.

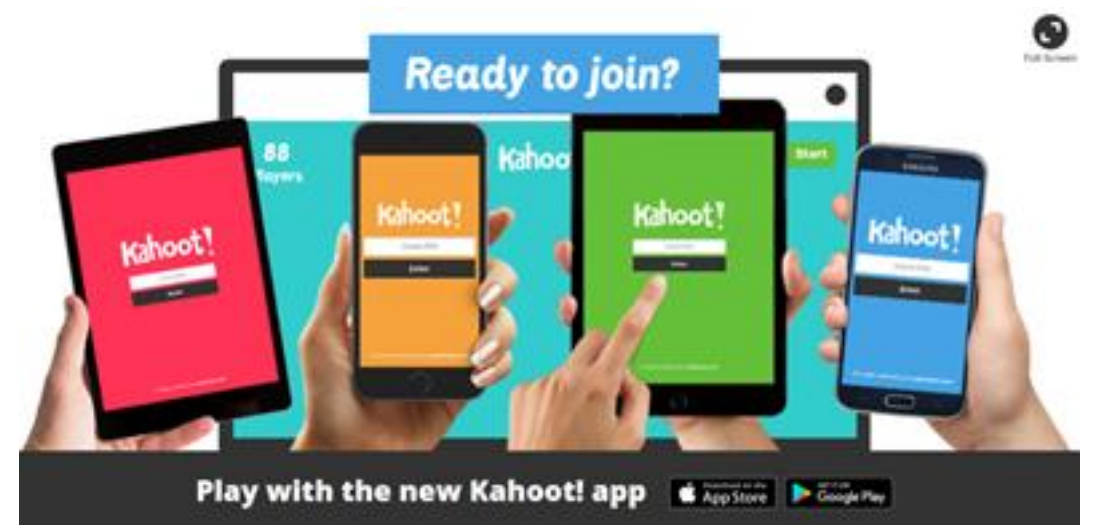

Figura 1: layout do aplicativo Kahoot.

Fonte: os autores

Para essa atividade, apegamo-nos à orientação de Vigotsky (1998), ao afirmar que, para o aprendiz organizar seu pensamento, o brincar e o jogar são vitais, pois desvenda a situação cognitiva, visual, auditiva, tátil e motora, proporcionando a melhoria no relacionamento com eventos, pessoas, coisas e símbolos. Apresentada, então, a forma de construção da atividade no Kahoot, foi necessário problematizar o papel desse instrumento na sala de aula para fins didáticos e, principalmente, para fins de avaliação da aprendizagem, já que esse foi o principal interesse do grupo e que motivou o assunto sobre o lúdico e os aplicativos que têm cada dia mais se aproximado da escola e das salas de aula.

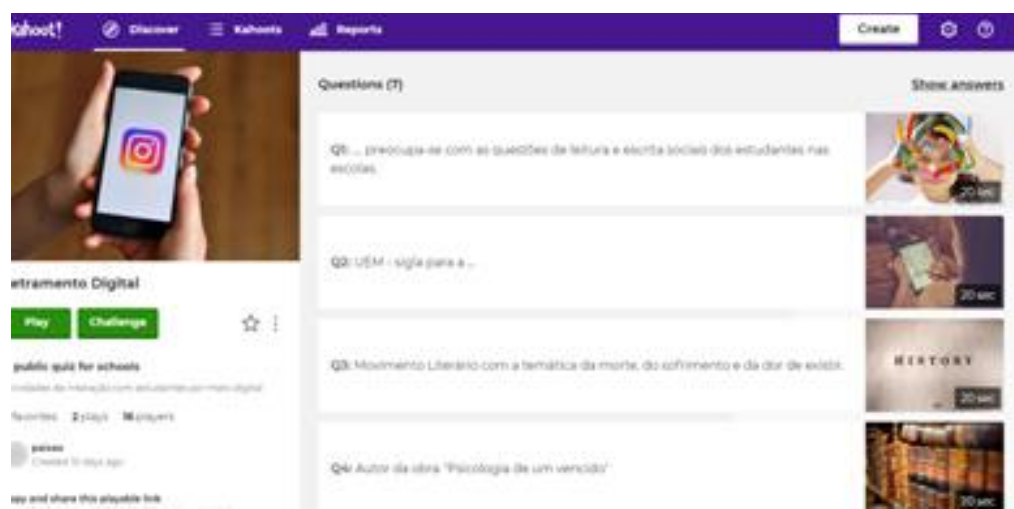

Figura 2: atividade com o aplicativo Kahoot desenvolvida com o grupo. Fonte: os autores 
Alguns acadêmicos, nesse momento de reflexões sobre o que foi construído, trouxeram suas considerações sobre o uso do App, questionando inclusive o fato de, como ocorreu no início da aula, a tecnologia deixar "o professor na mão" e não conseguir aplicar a atividade. Foi então que propusemos um diálogo sobre as imprevisibilidades que podem acontecer na sala de aula, seja com o uso dos artefatos da tecnologia ou sem eles e a forma como os professores podem lidar com isso, tendo sempre "uma carta na manga", ou seja, uma atividade extra já preparada em casos de imprevistos que podem ocorrer.

$\mathrm{Na}$ sequência, após as discussões sobre os assuntos referentes ao Letramento Digital, organizou-se um café com os alimentos e bebidas trazidas pelo grupo e, enquanto servíamos, discutimos a configuração das escolas na atualidade. A necessidade de se estabelecer uniformemente os tempos das aulas... das carteiras em filas indianas... os espaços de estudo... os materiais disponíveis...

Com a organização do café coletivo, demos início a um bate papo posterior sobre o sentido da expressão "Educação Integral", comentada com muita frequência nos últimos tempos pela chegada da Base Nacional Comum Curricular (BNCC), documento atual que orienta o trabalho pedagógico do professor brasileiro. $\mathrm{O}$ conceito de educação integral na qual a BNCC está comprometida se refere "à construção intencional de processos educativos que promovam aprendizagens sintonizadas com as necessidades, as possibilidades e os interesses dos estudantes, com os desafios da sociedade contemporânea" (BRASIL, 2017, p. 14).

É nessa direção, além do que já nos propusemos a argumentar a favor do tratamento dado às questões inerentes ao uso das tecnologias para fins didáticopedagógicos, que caminhamos para que reflexões surjam no campo das ciências da educação e da linguagem. A observação das necessidades, possibilidades e interesses dos estudantes promove de forma efetiva a ressignificação do currículo escolar, que deixa de ser um território inerte e passa a se tornar um espaço de constantes inovações, adaptações e conflitos e disputas de interesses individuais e coletivos (ARROYO, 1994).

Problematizamos juntos, a partir do conceito de currículo e de educação integral, a importância da educação emocional dos alunos nas escolas aparelhadas a uma educação cognitiva em que, assim como naquele café organizado por todos, é possível a criação de ambientes de aprendizagem que aliem esses dois polos, ou seja, cognição e afetividade, em projetos de ensino (BENDER, 2014) em qualquer área do conhecimento escolar (ARANTES, 2003). Uma educação integral que emerge em uma escola preocupada com a integração dos alunos nos meios sociais em que circulam e que insere em seu cotidiano o papel dos "afetos, dos sentimentos, das emoções, e dos valores, e precisa reorganizar seus conteúdos e os espaços, os tempos e as relações interpessoais" (ARAÚJO, 2003, p. 163).

Ao término do café, após a discussão sobre o conceito de Educação Integral, principalmente a partir do que propõe a BNCC, partimos para uma última atividade prática planejada para aquele curso, que era a de os acadêmicos pesquisarem em suas redes sociais as produções escritas e suas expressões de sentimentos, aproximando-lhes ao conceito de entonação expressiva (BAKHTIN, 2013), tema de nosso projeto de pesquisa no estágio pós-doutoral, o que nos deu a abertura para estar com os acadêmicos naquele encontro.

Os participantes compreenderam e, de modo afirmativo, posicionaram-se sobre a importância do papel da escola na formação de pessoas que pensam, aprendem, mas que "também sentem", entendendo que esse compromisso não é só da família, mas também 
da escola, por via de projetos interdisciplinares (BENDER, 2014). Ao longo de aproximadamente vinte minutos, todos os participantes puderam avaliar em suas redes sociais na internet as manifestações dos afetos de seus "amigos" virtuais e relataram, por fim, que nunca haviam pensado nesse contexto de produção escrita como um espaço que facilita a produção dos desabafos, dos xingamentos, das críticas etc., por serem textos virtuais sem a preocupação com o interlocutor que se encontra distante fisicamente (PAIXÃO, 2012; 2016).

Para finalizar o encontro, organizamos um grande círculo na sala de aula para assistirmos a um vídeo que trata especificamente do assunto: "A escola da atualidade". O vídeo intitulado "Aprendizagem Interativa e Dinâmica", disponível no Youtube (https://www.youtube.com/watch?v=HH0xTA2RkoE), propõe uma discussão sobre o papel da escola nos dias de hoje, mostrando, de forma criativa, a defesa de que a escola precisa acompanhar os processos de desenvolvimento social, como aconteceu com as empresas e os objetos, como carro e telefone, por exemplo, como são apresentados no vídeo. Na sequência, convidamos todos a produzirem, em pequenos pedaços de papel distribuídos aos participantes, avaliações do trabalho desenvolvido nos dois dias de curso, sem a utilização da escrita, mas em forma de dobraduras, desenhos, sinais ou qualquer outra manifestação. O propósito era ainda o de problematizar a linguagem não verbal como construtora de sentidos nos mais variados contextos de produção, aplicando a auto avaliação reflexiva, de acordo com as proposições de Bender. (2014).

$\mathrm{O}$ último dia do encontro foi finalizado com agradecimentos a todos os participantes e ao supervisor desse trabalho que orientou e colaborou de modo significativo para a organização daquele encontro com os acadêmicos e pela oportunidade de estar ali ensinando e aprendendo com o grupo, deixando-lhes palavras de incentivo para a prática docente e sugerindo bibliografias para aprofundamento da teoria utilizada naqueles dois momentos do curso.

\section{Considerações Finais}

A participação dos acadêmicos ao longo do curso distribuídos nos dois dias de encontro ocorreu de maneira bastante ativa, produtiva e satisfatória. Das avaliações realizadas por eles, a partir dos conteúdos apresentados na teoria e na prática, emergiram ideias e motivações em se pensar a sala de aula e, principalmente, a aula de Língua Portuguesa, a partir de uma reconstrução dos espaços de aprendizagem. Como professores que trabalham em outras instituições de ensino, tivemos a oportunidade de experimentar e conhecer novos perfis de alunos de graduação e perceber a necessidade de planejamentos contínuos nas atividades na formação de professores que esperam inovações nos modos de ensinar e avaliar os estudantes.

As indagações e os posicionamentos dos acadêmicos durante todo o período do curso colaboraram significativamente para que pudéssemos repensar estratégias de aplicação de atividades e orientação de leituras colaborativas nos próximos cursos que venhamos a ministrar, seja na universidade, seja na formação continuada de professores.

Todos os conteúdos planejados no cronograma inicial foram trabalhados a contento, porém, alguns deles com maior ênfase, como, por exemplo, a avaliação da aprendizagem, que foi o tópico de maior interesse do grupo, por isso, foi necessária uma abordagem diferenciada do planejamento inicial. $\mathrm{O}$ interesse dos participantes sobre o assunto do Letramento Digital foi maior do que esperávamos. A turma se mostrou comprometida e interessada em todas as propostas apresentadas, por isso, obtivemos o sucesso esperado. 
Para nossa prática pedagógica, a oportunidade de ministrar esse curso foi de extrema importância. Pudemos avaliar nossa prática, principalmente na organização e no planejamento dos cursos que ministramos com professores em nossa rotina de trabalho. Estando diante de acadêmicos e cursistas que fazem parte de outro contexto universitário, que não o nosso, pudemos perceber a constante e necessária reavaliação e replanejamento das práticas de sala de aula, principalmente quando se trata de trabalho com a formação de professores.

A exigência de oferecer um curso dentro dos requisitos do estágio pós-doutoral é uma excelente iniciativa do Programa de Pós-Graduação. Para nós, de forma prática, pudemos conhecer contextos de formação inicial de professores que nos fizeram refletir e repensar nossas atividades à frente da formação de professores, bem como dos tópicos que emergiram durante o curso e que foram temas de nossas discussões. Além disso, e tão importante quanto, a supervisão realizada pelo professor orientador do estágio pósdoutoral, com suas indagações, provocações e exigências, colaboraram para a preparação de um curso com qualidade e, naturalmente, reflexões para práticas futuras em cursos da mesma natureza.

\section{Referências}

ARAÚJO, Ulisses F. A dimensão afetiva da psique humana e a educação em valores. In: ARANTES, Valéria Amorim (Org.). Afetividade na escola: alternativas teóricas e práticas. São Paulo: Summus, 2003.

ARROYO, M. Escola Plural. Proposta pedagógica Rede Municipal de Educação de Belo Horizonte. Belo Horizonte: SMED, 1994.

BAKHTIN, Mikhail: Marxismo e filosofia da linguagem. São Paulo: Hucitec, 2013.

BENDER, Willian N. Aprendizagem baseada em projetos: educação diferenciada para o século XXI - Porto Alegre: Penso: 2014.

COSCARELLI, Carla Viana. Entre textos e hipertextos. In: (Org.). Novas tecnologias, novos textos, novas formas de pensar. 3. ed. Belo Horizonte: Autêntica, 2006. p. 65-84.

Tecnologias para aprender. 1. ed. - São Paulo: Parábola Editorial, 2016.

; RIBEIRO. Ana Elisa. (Org.) Letramento Digital: aspectos sociais e possibilidades pedagógicas. 2. ed. Belo Horizonte: Ceale; Autêntica, 2007.

FERREIRA, Helenice Mirabelli Cassino; OSWALD, Maria Luiza Magalhães Bastos; CHAVES, Sarah Nery Siqueira. Juventude, pesquisa e contemporaneidade: Pensando com os jovens o rejuvenescimento do mundo. In: PEREIRA, Rita Marisa Ribes; SANTOS, Núbia de Oliveira; LOPES, Ana Elisabete Rodrigues de Carvalho. (Org.). Infância, juventude e educação: práticas e pesquisas em diálogo. 1. ed. Rio de Janeiro: Nau Ed., 2015.

MORENO, M.; SASTRE, G. O significado afetivo e cognitivo das ações. In: ARANTES, V. A. (Org.) Afetividade na escola: alternativas teóricas e práticas. São Paulo: Summus, 2003. p. 87-106. 
PAIXÃO, Sergio Vale da. Produção escrita e Letramento Digital: Interfaces na escola e nas redes sociais. Londrina, 2012.

Sentimentos na rede e educação: um estudo a partir das narrativas de jovens nas redes sociais. Curitiba: CRV, 2017.

PRENSKY, Marc. Digital Natives, Digital Immigrants. MCB University Press, 2001. Disponivel

em:

<http://www.marcprensky.com/writing/Prensky\%20\%20Digital\%20Natives, \%20Digital $\% 20$ Immigrants\%20\%E2\%80\%90\%20Part1.pdf>. Acesso em: 05 out. 2016.

RIBEIRO, Ana Elisa. Novas Tecnologias para ler e escrever. Algumas ideias sobre ambientes e ferramentas digitais na sala de aula. Belo Horizonte: RHJ, 2012.

ROJO, Roxane Helena R.; MOURA, Eduardo. (Org.) Multiletramentos na escola. São Paulo: Parábola Editorial, 2012.

SANTOS, Camila Matizenauer.; BIANCALANA, Gisela Reis. Autoetinografia: um caminho metodológico para pesquisa em artes performativas. Revista Aspas. Vol. 7. N.2. 2017

TARDIF, Maurice. Saberes docentes e formação profissional. 9. ed. Petrópolis: Vozes, 2008.

Recebido em 16 de janeiro de 2020

Aceito em 24 de abril de 2020 